\title{
LA EMERGENCIA DEL CONFLICTO RELIGIOSO EN el municipio de Las Margaritas, Chiapas: El Caso Del ejido Justo Sierra ${ }^{1}$
}

\author{
Miguel Lisbona Guillén
}

$\mathrm{D}$ esde principios de los años noventa, del pasado siglo, la prensa local y nacional reflejó la incipiente conflictividad que, por supuestos motivos religiosos, se producía en el municipio de Las Margaritas (Chiapas). Por una parte se encontraban los problemas motivados por la fricción e incluso expulsión de evangélicos de distintas localidades (Saltillo); ${ }^{2}$ por otra, estaban los relacionados con el papel jugado por sacerdotes de la diócesis de San Cristóbal de Las Casas, algunos incluso tildados de guerrilleros antes de 1994. ${ }^{3}$ A pesar de estas dos vertientes de conflictividad y de los tiempos previos al alzamiento neozapatista en que se producen, no será hasta después de 1994 cuando el municipio, que concentra la problemática religiosa regional, ${ }^{4}$ observará un notable incremento en el número de controversias, de carácter violento algunas, asumidas como religiosas.

En las siguientes líneas exploraremos el desarrollo de uno de estos conflictos considerados, de manera inicial, como religioso, para mostrar que la explicación ceñida a esta única vía de análisis conduce a una interpretación parcial, ajena a los elementos sociológicos que inciden en el surgimiento y desarrollo de los conflictos regionales.

Miguel Lisbona Guillén, PROIMMSE-IIA-UNAM.
La localidad de Justo Sierra se encuentra ubicada en la microrregión, desde la perspectiva de la Presidencia Municipal, conocida como "Tojolabal", 5 territorio que ha concentrado buena parte de los conflictos denominados religiosos de Las Margaritas. Desde Comitán, si seguimos la carretera que conduce hacia el municipio de Altamirano, se encuentra el desvío que nos lleva, después de un breve recorrido de terracería, al ejido en cuestión.

Su calidad de ejido, como ocurre con buena parte de las localidades vecinas, tiene su origen en la denuncia y posterior adjudicación de tierras que pertenecían a fincas hasta la aplicación de las leyes de reforma agraria en Chiapas, como ocurrió con buena parte de los territorios habitados por tojolabales a finales de los años treinta y cuarenta del siglo Xx.

En la primera mitad del año 1936, 37 personas del poblado Los Ateos, que no sabían firmar, solicitan al gobernador del estado la dotación de ejidos por carecer de tierra propia. La obligación de vender su trabajo a bajo precio y el descuidar la educación de sus hijos, reiterada expresión en las solicitudes del agro chiapaneco de aquellos y posteriores años, les conduce a demandar las tierras de la finca San Francisco, ${ }^{6}$ propiedad de Agenor Culebro. ${ }^{7}$ De esta manera iniciaba un proceso largo y poco nítido, en muchas ocasiones, 
para hacerse de las tierras que hoy conforman el ejido en cuestión. ${ }^{8}$

\section{II}

Para el pastor Antonio Alfaro, Coordinador de Asuntos Religiosos en la administración municipal de Las Margaritas (2002-2004), los conflictos relacionados con la intolerancia religiosa en la región habitada por tojolabales se han debido, en su mayoría, a los acuerdos surgidos de las asambleas comunitarias, especialmente en los lugares donde la Central Independiente de Obreros Agrícolas y Campesinos (CIOAC-Histórica) ha tenido un peso relevante. ${ }^{9}$ Sin embargo, en los últimos meses la mediación de las autoridades estatales, del ayuntamiento y, especialmente, la marcha atrás en la confrontación con los evangélicos llevada a cabo por Luis Hernández, diputado y líder cioaquista, han evitado la proliferación de los llamados problemas religiosos. En buena medida se puede afirmar que se cambiaron votos por supuesta defensa de la tradición; hecho este último relacionado con la percepción que las organizaciones campesinas ligadas al Partido de la Revolución Democrática (PRD), y el mismo partido, gobernante en el último mandato municipal, han tenido del crecimiento evangélico como una posibilidad de asegurar votos hasta ahora inexistentes por los ataques que sufrieron en los últimos años los no católicos.

No es casual que con anterioridad a este periodo de cierta estabilidad o cese de conflictos apareciera una organización, la OPET, Organización de Pueblos Evangélicos Tojolabales, que agrupa a más de 20 Iglesias Renovadas Presbiterianas, una escisión en el presbiterianismo regional que se ha decantado por una pentecostalización de sus ritos y, al mismo tiempo, ha centralizado la toma de decisiones hacia cada iglesia (pastor y consejo de ancianos); aunque el pastor Antonio Alfaro indica que su salida del Presbiterio Nacional respondió a la poca atención que recibían de los "mestizos". ${ }^{10}$ Esta organización, en relación con otras de carácter estatal y nacional, se dio a la tarea de defender a los evangélicos de las agresiones que sufrieron, especialmente, en la década pasada.

El caso de Justo Sierra se enmarca, por lo tanto, en un proceso regional más amplio. A pesar de sus singularidades responde a una problemática extendida en ciertas localidades tojolabales y, a la vez, cuenta con diferencias respecto a los conflictos religiosos más conocidos en Chiapas, concretamente los vividos en los Altos de Chiapas, en el municipio de Chamula.

Después de las elecciones para gobernador del estado, celebradas en julio del año 2000, aparecen los primeros indicios de que la situación religiosa en Justo Sierra puede derivar en algún tipo de conflicto, aunque tanto los católicos como las familias adventistas y pentecostales del lugar lo nieguen. Sin embargo, estos últimos ya apuntaban el malestar existente entre los primeros por ser ellos votantes del Partido Revolucionario Institucional (PRI), partido que perdió las elecciones arriba mencionadas. ${ }^{11}$

Estos atisbos de conflicto se incrementaron cuando las familias no católicas del lugar afirmaron que en una reunión celebrada el día 8 de octubre del año 2000 en su localidad, con la participación de los cargos públicos locales, militantes de la CIOAC-Histórica todos ellos, se intentó presionar a los priistas para que no brindaran apoyo a sus correligionarios de distinta religión a la tradicional, así como insinuaban posibles acciones contra los mismos después de la festividad de Todos los Santos. ${ }^{12}$ Lo anterior se consideró, por los funcionarios de la Subsecretaría de Asuntos Religiosos, una señal de posible conflicto, por lo que se pidió al Procurador de Justicia las garantías correspondientes para las familias implicadas. ${ }^{13}$

La alta incidencia de conflictos religiosos desatada en la década de los noventa en el municipio de Las Margaritas motivó una reunión con las partes implicadas en la cabecera municipal. Con la asistencia de funcionarios públicos, representantes ejidales y de los no católicos, el 26 de octubre se confrontaron opiniones y 
denuncias, estas últimas negadas por los católicos en voz de las autoridades ejidales. Lo anterior motivó que la minuta de trabajo efectuada al finalizar la misma expresara que

Los representantes de las dependencias consideramos inoportuno insistir sobre la elaboración de un documento firmado y sellado por la asamblea desmintiendo las acusaciones, por que (sic) esto implicaba convocar y explicar en forma detallada a todos los ejidatarios las acusaciones de que estaban siendo objeto así como señalar nombres de acusadores, y en esta reunión podrían resultar opiniones que agudizaran las pocas diferencias que existen, además de crear un clima de rencor en contra de quienes no profesar la religión católica. ${ }^{14}$

Curiosamente, el mismo día en que se llevó a cabo la reunión anterior, el periódico Novedades de la Ciudad de México había publicado una nota en la que se mencionaba el posible conflicto en el ejido Justo Sierra, hecho que causó que el visitador adjunto de la Comisión Estatal de Derechos Humanos enviara un oficio al Secretario de Gobierno y otro del Director de Asuntos Jurídicos del Gobiemo del Estado al Subsecretario de Asuntos Religiosos, ambos en la misma fecha, el 26 de octubre, y con la preocupación de que lo denunciado por los no católicos del lugar pudiera concretarse. ${ }^{15}$

El cambio de autoridades estatales, tras la toma de posesión del nuevo gobernador, Pablo Salazar Mendiguchía, así como las festividades navideñas, significaron un receso en la participación de las dependencias oficiales en el incipiente conflicto, sin embargo, a principios del año 2001 éste tomó nuevos bríos, especialmente porque un acta de acuerdo ejidal, donde los representantes evangélicos estamparon su firma, señalaba que

...nos encontramos reunidos en la cancha ejidal, todos los ejidatarios de esta comunidad por invitación de las autoridades ejidales y el agente municipal de este lugar, para trata el asunto relacionado con las familias que han dejado su religión católica por otra evangélica, las autoridades por su parte los invita(sic) a estas familias a que trabajen, cooperen y continúen en la comunidad, dejando la religión que ahora profesan, pero estas familias se ponen de acuerdo y que son veinti cuatro(sic), manifestando que no dejarán su religión y que para no tener problemas posteriores en la comunidad mejor se separarán de este lugar por su propia boluntad(sic) sin que tengan presión alguna, la misma comunidad les propone a las familias que si con el tiempo no pueden vivir en otro lugar y quieren regresar pueden hacerlo siempre y cuando se comprometan a trabajar, cooperar y dejar la religión que hoy profesan, pueden reconocer sus tierras y pueden llevarse todas sus pertenencias a partir de esta fecha en un mes... ${ }^{16}$

La anuencia de los representantes evangélicos no era congruente con su actitud posterior, ya que un día después visitaron al delegado del gobierno en la región Fronteriza para indicarle que firmaron bajo amenaza. A partir de este momento, y durante el tiempo que durará el conflicto, los no católicos apelarán a sus derechos como ciudadanos mexicanos reconocidos en el artículo 24 constitucional y solicitarán al gobierno que cumpla sus obligaciones en la defensa de las libertades individuales, ${ }^{17}$ aspecto que ya era atendido a partir de entonces cuando el nuevo Subsecretario de Asuntos Religiosos solicitaba la presencia de la Seguridad Pública estatal para desplegar las medidas precautorias y cautelares correspondientes; ${ }^{18}$ medidas que eran solicitadas también, unos días más tarde, por el delegado de gobierno regional. ${ }^{19}$

La situación de la región fronteriza requería una atención minuciosa por parte de los funcionarios públicos encargados del rubro religioso; por tal motivo a principios del mes de febrero el Subsecretario de Asuntos Religiosos se desplazó a la región para sostener reuniones con los involucrados y para atender los con- 
flictos suscitados en Plan de Ayala, Justo Sierra, 20 de Noviembre, Nuevo México y San Carlos del Río. ${ }^{20}$ Como declaración previa a las reuniones que sostendría en el municipio de Las Margaritas, un oficio dirigido a las autoridades de Justo Sierra sentaba la posición de la Subsecretaría:

Comunico a ustedes que esta Subsecretaría tiene conocimiento que el 11 de enero del presente año, en esa localidad levantaron un acta mediante la cual, 24 familias evangélicas, supuestamente de manera voluntaria aceptaron abandonar dicha comunidad. $\mathrm{Al}$ respecto, les informo que el Estado mexicano garantiza a favor del individuo, entre otros, tener o adoptar la creencia religiosa que más le agrade y practicar, en forma individual o colectiva, los actos de culto o ritos de su preferencia y no ser objeto de discriminación, coacción u hostilidad por causa de sus creencias religiosas. En virtud de lo expuesto, en su carácter de autoridades internas de esa comunidad, mucho agradeceré de ustedes hagan saber lo anterior a los miembros de la misma, para la debida observancia de las disposiciones legales señaladas; esto con el fin de evitar la posible violación de los derechos humanos y la consecuente comisión de delitos de orden penal. ${ }^{21}$

Ante la inminente conclusión del plazo de un mes, establecido en el acuerdo de asamblea firmado el día 11 de enero, para que los evangélicos abandonaran la localidad, se produjo una reunión el día 8 de febrero en la Delegación de Gobierno Fronteriza, en la que participaron las autoridades ejidales y locales, miembros de la CIOAC que respaldaban a éstas, concretamente Luis Hernández Cruz y José Antonio Vázquez, así como representantes de los amenazados de expulsión, líderes de la Organización de Pueblos Evangélicos Tojolabales (OPET), Antonio Alfaro Aguilar, José Roque Hernández y José Guadalupe Méndez Pérez. En la misma los amenazados aceptaban ser reubicados en un anexo territorial del mismo ejido, aunque no acep- taron el lugar propuesto por las autoridades comunitarias, hecho que rompió la negociación y desplazó la fecha de expulsión al día 28 de febrero. ${ }^{22}$

La negociación, como en buena parte de las que han acontecido en la región, no sólo ponía de relieve la imbricación de intereses políticos y religiosos, sino que estaba marcada por las solicitudes de los negociadores en aspectos que trascendían el hecho que los sentaba a la mesa de debate. Es decir, tanto los católicos como los evangélicos ponían condiciones al gobierno para aceptar los acuerdos, los primeros al solicitar la creación de una preparatoria, la conversión de la telesecundaria en secundaria técnica, la construcción de viviendas y el sistema de agua potable; mientras que los segundos consideraban todas las necesidades de infraestructura en la nueva localidad, ${ }^{23}$ así como el apoyo en proyectos productivos. ${ }^{24}$ De tal manera que buena parte de los conflictos desatados en el municipio de Las Margaritas, pero no como singularidad local, posibilitan que la futura solución esté condicionada a negociaciones paralelas de infraestructura o servicios que no tienen nada que ver con el origen del conflicto. Forma velada de presentar las carencias estatales a la par que las dificultades de financiación locales.

Igualmente, la creación de un anexo ponía sobre el tapete de la discusión la incapacidad del Estado mexicano y de las autoridades chiapanecas para cumplir con su deber de ser garante de los derechos individuales de sus ciudadanos y recordaba, sin lugar a dudas, la política segregacionista que se llevó a cabo en Chiapas desde las primeras expulsiones de evangélicos en la región Altos en los años setenta del siglo pasado. La supuesta gobernabilidad y la ocultación del conflicto se anteponían al cumplimiento estricto de la ley, a la salvaguarda de la libertad de creencias en este caso. ${ }^{25}$

Aunque esta vía de solución fue en un principio aceptada por los no católicos, fueron ellos quienes pusieron en entredicho la misma, puesto que en una carta fechada el 20 de febrero le indicaban al Subse- 
cretario de Asuntos Religiosos que las familias involucradas acordaron

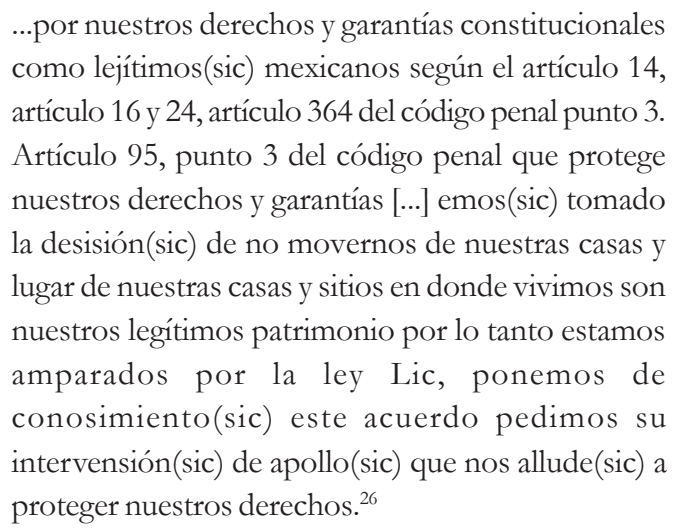

Los evangélicos se asumían, desde entonces, como los defensores de la legalidad vigente y cuestionaban la política llevada a cabo durante más de 30 años por las instituciones estatales para solventar la conflictividad religiosa, hecho que repercutiría finalmente en la solución del conflicto y en la actitud tomada a partir de entonces por el gobiemo estatal.

Como se observó en párrafos anteriores, la inclusión del conflicto de Justo Sierra en la prensa nacional provocó la inmediata preocupación y respuesta por parte delos funcionarios públicos estatales. Una nota del caso aparecida en febrero también en el periódico Novedades, y remitida por el visitador de la Comisión Estatal de Derechos Humanos al Secretario de Gobierno movilizó de nuevo a las instancias públicas, ${ }^{27}$ pero no sólo a ellas, como veremos más adelante. Un día después era informado el Subsecretario de Asuntos Religiosos y se le solicitaba la intensificación de su labor, ${ }^{28}$ la cual iniciaba con la solicitud de medidas cautelares ante la posible expulsión de los evangélicos. ${ }^{29}$ Las medidas llegaron tarde, al menos para evitar que el 23 de febrero varios amenazados de expulsión fueran agredidos físicamente, después de ser sacados violentamente de la casa en la que reunidos discutían su permanencia en la localidad.
Al siguiente día los agredidos, que habían abandonado la localidad por temor a que se incrementara la violencia, presentaron una denuncia ante el ministerio público correspondiente, ${ }^{30}$ acusando a las autoridades del ejido, "pertenecientes al PRD y al grupo de Luis Hernández de la CIOAC". ${ }^{31}$ Ese mismo día, el 24 de febrero, remitieron también un escrito dirigido al Delegado de Gobierno en la región y firmado por "Los Expulsados"; en el mismo pedían

\footnotetext{
...rescatar a nuestras familias que se quedaron en nuestra Comunidad. Detenidas por las Autoridades rurales del lugar y que no los dejan salir para venir a buscarnos pues ellas no saben en donde nos encontramos, tememos por su integridad física por lo que le solicitamos muy urgentemente buscar los medios posibles con el apoyo de la Seguridad Pública para rescatar a nuestras Familias toda vez que nos encontramos en la agencia del Ministerio Público de esta Ciudad de Comitán... ${ }^{32}$
}

La tensión en la localidad no era nueva, como se ha podido comprobar en la narración de los hechos, pero el desencadenante de la misma, según sus autores, fue la publicación de la nota periodística en la que los evangélicos se negaban a abandonar su localidad para trasladarse a un anexo. ${ }^{33} \mathrm{El}$ delegado gubernamental en la región mantuvo ese mismo día reuniones con los implicados de ambas partes, concertando con los expulsados que sus familias no saldrían de Justo Sierra, así como se intensificaría la seguridad pública y se les apoyaría con alimentación y vivienda mientras permanecieran desplazados, ${ }^{34}$ en un principio en el barrio "El Cedro" de Comitán. $^{35}$

Por otra parte, los partidarios de las expulsiones, encabezados por los líderes de la CIOAC-Histórica, reunidos con un operador político del gobierno estatal se negaron a dialogar con algún funcionario que no fuera el Gobernador del Estado o el Secretario de Gobierno, 
al igual que condicionaban la solución del caso Justo Sierra a la problemática suscitada en la localidad 20 de Noviembre, también del municipio de Las Margaritas. ${ }^{36}$

Antes de establecer cualquier tipo de negociación, las familias de los inicialmente golpeados pudieron salir del ejido Justo Sierra y sostuvieron una reunión con el gobernador el día 4 de marzo. Fecha anterior a su reubicación en las instalaciones del gimnasio municipal (Auditorio Municipal) de Las Margaritas. En total 26 familias, 25 evangélicas y una católica. Esta última temerosa de las posibles represalias por haber intentado mediar en el conflicto suscitado. Igualmente, una vez instalados en la cabecera municipal se les unieron 2 familias que ya habían abandonado la localidad desde hacía más de un año por los mismos motivos. ${ }^{37}$

Uno de los aspectos a destacar, tras la reunión con el gobernador, es que sólo reconocieron al CEDECH (Comité Evangélico de Defensa Evangélica de Chiapas) como el único representante jurídico ante las instancias pertinentes, ${ }^{38}$ aunque la OPET siguió siendo el cauce para las negociaciones, como lo demuestra sus acercamientos con el Delegado de Gobierno en la región; funcionario que también mantuvo contactos con los miembros de la CIOAC [histórica] tras la reubicación de los desplazados. El resultado de dichos encuentros fue las solicitudes disímiles de las organizaciones. Mientras que para la evangélica la prioridad era preservar el estado de derecho y, por lo tanto, el retorno de las familias a su localidad de origen, los militantes de la CIOAC propusieron la creación de un anexo para acomodar a los no católicos o el posible regreso de 20 familias, sin importar su credo, aspecto que dejaba fuera a 5 familias consideradas como las "causantes [...] de la división política y religiosa de la comunidad". Junto a ello se solicitaba al gobernador la introducción del agua entubada y su anuencia para que funcionara una preparatoria en Justo Sierra. ${ }^{39}$

Los desplazados no cejaron en su empeño de regresar a su localidad. El 13 de marzo enviaron cartas a diversas instancias estatales y federales. Al Subsecretario de Asuntos Religiosos le pidieron conformar una "Comisión Negociadora" para solventar el problema; ${ }^{40} \mathrm{al}$ Gobernador del Estado le solicitaban "Justicia, regreso y garantía contra cualquier amenaza”, además de negar una posible huelga de hambre, tal como había aparecido en la prensa local. ${ }^{41}$ Sin embargo, un comunicado que circulaba en las mismas fechas, a "los gobiernos federal y estatal. A la Procuraduría General de Justicia y la Comisión Nacional y Estatal de Derechos Humanos. A las organizaciones sociales no gubernamentales" señalaba lo contrario, puesto que se pedía

...a los gobiernos y autoridades quienes competen aplicar el estado de derecho resolver en un máximo de 72 horas por lo contrario iremos el conjunto de desplasados (sic) a una huelga de ambre (sic) ante una oficina gubernamental y declaramos reingrezar (sic) a las filas de la CIOAC independiente para que juntos con sus agremiados solo[...] nuestros problemas. ${ }^{42}$

Lo anterior no sorprende puesto que tanto las amenazas de expulsión, como las expulsiones mismas, han sido en la región objeto de disputa en pos de espacios políticos y de representación. Por lo tanto ha sido muy común que los involucrados tuvieran que negar sus nexos con ciertas organizaciones o líderes que se asumían como sus asesores. Este es el caso de Luis Jiménez Aguilar, quien se atribuyó la representación de los expulsados de la localidad Plan de Ayala, del mismo municipio de Las Margaritas, y que hizo lo propio en el caso de Justo Sierra, puesto que el mismo 13 de marzo declaró, como asesor de los evangélicos expulsados, que se llevarían a cabo diversas movilizaciones el día 16 en Comitán y Las Margaritas para reclamar el encarcelamiento de los líderes de la CIOAC, Luis Hernández Cruz y Antonio Hernández Vázquez, la destitución del Delegado de Gobierno en la región, así como efectuar un público reconocimiento al que fuera gobernador, Roberto Albores Guillén, por aplicar el estado de derecho. ${ }^{43}$ 
Este vaivén de siglas y nombres que aparecen en los casos de expulsión se confirmó cuando el día 21 de marzo miembros del CEDECH de Las Margaritas, Comitán e Independencia llevaron a cabo una marcha que recorrió las calles de la cabecera municipal de Las Margaritas, en la que con pancartas reclamaban el cumplimiento de los principios constitucionales y justicia contra los agresores causantes de la expulsión de las familias evangélicas. ${ }^{44}$

Las autoridades estatales han sido conscientes de que el trasfondo, de buena parte de los conflictos religiosos desatados en la región, es de naturaleza política y las posibles soluciones se establecen a partir de esa certeza. En el caso que nos atañe el Delegado de Gobierno en la región, lo dejaba muy claro cuando el 26 de marzo se dirigió al Secretario de Gobierno para señalarle que lo adecuado era sentar a las partes en conflicto, donde se incluía a la OPET y la CIOAC [Histórica], para llegar a acuerdos. De la misma manera que aseguraba que

Es necesario que no se apliquen las órdenes de aprehensión en virtud de que existen las condiciones para que las familias regresen a su lugar, y solo en caso de que la mesa de RECONCILIACIÓN, no cumpliera con su cometido se debiera de aplicar el Estado de Derecho. [Por lo anterior -asentaba- es necesario] Evitar que los Evangélicos, busquen la participación de la CIOAC INDEPENDIENTES, ya que "POLITIZARÍA", y agudizaría la pronta solución en virtud de ser organizaciones antagónicas. ${ }^{45}$

Es decir, el estado de derecho sólo era aplicable en caso de que los acuerdos paralegales fracasaran, al mismo tiempo que se temía una mayor participación política, puesto que desde un principio ésta fue clara por parte de los miembros de la CIOAC oficial o histórica, como así lo sabían los funcionarios públicos que conocían los acuerdos de dicha organización para evitar el retorno de ciertas familias evangélicas a Justo Sierra. ${ }^{46}$
Mientras lo anterior ocurría, los evangélicos desplazados solicitaban apoyos diversos para continuar con sus actividades cotidianas. Uno de ellos se refería a la vigilancia del lugar donde se albergaban, por temor a ataques de los católicos de Justo Sierra, ${ }^{47}$ mientras que otro se concretaba en el pago del transporte para los hijos que asistían a la escuela. ${ }^{48}$

La primera reunión con miembros de la CIOAC Histórica, tras el cúmulo de desencuentros surgidos a raíz del desplazamiento de las familias evangélicas, tuvo lugar el 6 de abril en las oficinas del Comisionado para la Reconciliación de Comunidades en Conflicto, ubicada en San Cristóbal de Las Casas. Las propuestas de la CIOAC admitían el retorno de los evangélicos, con posterior mesa negociadora que discutiera, en primer lugar, la creación de un anexo. ${ }^{49}$ Uno de los compromisos que se acordaron fue continuar las reuniones, hecho que llevó a cabo el Subsecretario de Asuntos Religiosos el 27 de marzo, concretamente en la cabecera municipal de Las Margaritas y con miembros de la CIOAC Histórica. De la cual resultó un acuerdo para dialogar con autoridades y ejidatarios de Justo Sierra. ${ }^{50}$

La negociación, por lo tanto, privilegiaba la interlocución de los agresores por encima de las solicitudes de los agredidos. Hecho evidente si se toma en cuenta la carta que con papel membretado del CEDECH dirigen los representantes de los expulsados al Subsecretario de Asuntos Religiosos, con copia al Gobernador del Estado. En ella se podía leer lo siguiente:

Que con el presente memorial y con fundamento en el artículo $8^{\circ}$ de la Constitución General de la República, solicitamos muy atentamente se nos informe a la brevedad si ésta Subsecretaría a su digno cargo tiene la voluntad política de solucionar el problema cuya denuncia ya la conocen ampliamente [...], porque Usted sabe que no es posible lograr nuestro retorno por la vía del diálogo con los agresores de Justo Sierra toda vez que ellos son los que ponen sus condiciones y no 
respetan a las Autoridades y desafían al mismo Gobierno, pero insistimos necesitamos saber de manera inmediata si existe la posibilidad del C. Gobernador actual en corregir este cáncer social porque no es posible que continuemos como refugiados en las instalaciones del Auditorio Municipal [...], dejando abandonadas nuestras pertenencias que tenemos en nuestra Colonia, además de que expulsadores se pasean libremente e incluso se burlan porque hasta la fecha no se les detiene con la Orden de aprehensión que se giró en contra de ellos, dando la impresión que algún funcionario los protege.

Nuestras posturas ya las conocen ampliamente y queremos saber la verdad o en realidad Ustedes sabrán si hay que (sic) necesidad de acudir a un plantón indefinido frente al Palacio de Gobierno y que la opinión pública en todos los ámbitos conozca la carencia de justicia Social que existe en nuestro Estado. ${ }^{51}$

Esta extensa cita pone de manifiesto hasta qué punto los evangélicos carecían de la interlocución que consideraban les correspondía como agraviados, así como una posible connivencia con los expulsadores por parte de autoridades estatales. ${ }^{52}$ Síntoma similar se produjo cuando acudieron en el mes de junio al visitador de la Comisión Estatal de Derechos Humanos para plantearle su situación. ${ }^{53}$

La retahíla de acciones institucionales, solicitudes de los evangélicos o condiciones de los agresores tuvo un punto de inflexión con la detención, el 27 de junio de 2001, de tres personas de la localidad de Justo Sierra, las acusadas de ser los causantes de las agresiones. Se trataba de Guillermo Méndez Sántiz, Presidente de Comisariado Ejidal, Melquiades Hernández Méndez, Agente Municipal y Aureliano Sántiz Pérez, del Consejo de Vigilancia. ${ }^{54}$ El encarcelamiento de los inculpados provocó la movilización de funcionarios estatales en previsión de posibles represalias contra los evangélicos o alteraciones del orden público. ${ }^{55}$
Las congratulaciones por el cumplimiento de la ley, manifestadas por el CEIECH (Consejo Estatal de Iglesias Evangélicas de Chiapas), ${ }^{56}$ contrastaban con la urgencia de las reuniones planteadas por la CIOAC, ${ }^{57}$ o con la carta que autoridades encargadas de Justo Sierra dirigieron al gobernador, en la que le reclamaban el apoyo que le brindaron en su campaña electoral y afirmaban que no dialogarían hasta que salieran los presos, así como, en un tono amenazador, decían que

La minoría priista en la comunidad está provocando, asesorados por el Sr. Martín León Suares (sic) presidente Municipal de Las Margaritas, pedidimos (sic) su intervención para que deje de provocar. No estamos jugando.

Esperamos su respuesta favorable, en caso contrario habrá acciones. ${ }^{58}$

Los evangélicos, por su parte, solicitaron su retorno también al gobernador. Con un tono más moderado, pero con similares condicionantes a los expuestos por los católicos de la localidad. Su primer reclamo fue el incumplimiento de una rápida solución a la que se había comprometido el gobernador cuando los visitó en Comitán tras ser expulsados. Su retorno debía incluir a todas las familias, ser indemnizadas con 20,000.00 pesos y contar con la certeza jurídica de sus tierras. Todo ello en un plazo menor a los 15 días. De no cumplirse lo expuesto amenazaron con

...acudir a organismos de derechos humanos: Estatal, Nacional e Internacional para que se haga cumplir la legalidad, porque sentimos que nuestros derechos son cada vez más vulnerados y al aplicar el Estado de Derecho se nos garantizará una justicia social más digna, de igual forma haremos declaraciones de prensa para que sean escuchados nuestros reclamos porque no estamos de acuerdo seguir sufriendo como en la actualidad ocurre, ya que no es posible que una minoría 
de habitantes de una colonia como es el ejido JUSTO SIERRA es la que ponga las condiciones al Gobierno.

Esta solicitud la formulamos de acuerdo al Artículo

$8^{\circ}$ de la Constitución General de la República. ${ }^{59}$

Un mes más tarde, a pesar de las amenazas vertidas, volvían a dirigirse al gobernador con un tono totalmente distinto, ahora más de súplica y de conformidad que de reto: "Vamos a dialogar en pocos minutos nuestro regreso y el apoyo para estar en el lugar más conveniente, que usted nos diga de su propia voz" ${ }^{60}$

El encarcelamiento de los implicados en las agresiones contra los evangélicos había acelerado el desenlace del conflicto, aunque no estaba claro el rumbo que tomaría, especialmente porque a finales de agosto los desplazados fueron visitados por funcionarios estatales que repitieron las posibilidades que ya sabían, y que había sido condición de los católicos desde un principio: el retorno de las familias, a excepción de cuatro, o la creación de un anexo. Ante la posibilidad del anexo, que ahora no deseaban, pero que veían como solución, propusieron la construcción de viviendas e infraestructura necesaria; indemnización de 30,000.00 pesos por abandono de enseres domésticos y la legalidad jurídica del nuevo centro de población. ${ }^{61}$ Mismas condiciones que en forma manuscrita manifestaron al Delegado de Gobierno en la región dos meses más tarde. ${ }^{62}$

La situación, tal como estaba planteada, no parecía tener atisbos de solución, a no ser que el gobierno chiapaneco agilizara la construcción del anexo y lo dotara de los servicios necesarios para recibir a las familias que lo poblarían, sin embargo, a mediados del mes de noviembre se lograba firmar el Convenio de Reconciliación. ${ }^{63}$ Concretamente el día 16 en el municipio de Las Margaritas y con la presencia de representantes de diversas instancias gubernamentales, además de un representante de la CIOAC, se acordaba:
PRIMERO.- Las partes que firman el presente convenio, acuerdan de manera voluntaria y pacífica el retorno de las 25 familias que profesan la religión evangélica, siendo un total de 136 personas.

SEGUNDO.- Las partes que firman el presente convenio resuelven convivir de manera armoniosa en la comunidad Justo Sierra sin agredirse, respetando la integridad física, moral y patrimonial; proponiendo las partes la recomposición de nuevas reglas de convivencia pacífica en el interior de la comunidad. TERCERO.- Las partes se comprometen ha (sic) respetar y reconocer lo dispuesto en los artículos 24 y 130 de la Constitución Política de los Estados Unidos Mexicanos, que garantizan la libertad de creencias religiosas.

CUARTO.- Las partes se comprometen a reconstruir sus relaciones internas con respecto a las diferencias que existieron, reintegrándose las 25 familias a la comunidad con los mismos derechos y obligaciones en que venían realizando hasta antes del 23 de febrero del dos mil uno.

QUINTO.- Las partes acuerdan que todos los integrantes de la comunidad de Justo Sierra se comprometen recíprocamente a no provocarse moral y físicamente. SEXTO.- En el marco de la legalidad las partes se comprometen a respetar los usos y costumbres de la comunidad; comprometiéndose ha (sic) otorgar los apoyos necesarios para el desarrollo de estos.

SÉPTIMO.- Las partes acuerdan que se debe crear una comisión de dependencias de gobierno y organizaciones que dará seguimiento al cumplimiento de los acuerdos aquí adoptados.

OCTAVO.- Las partes manifiestan que en caso de incumplimiento de los presentes acuerdos, se someten a plantearlos en primera instancia a la comisión antes mencionada. ${ }^{64}$

Transcurrido casi un año desde que acontecieron los hechos causantes del abandono del ejido Justo Sierra por parte de las familias no católicas, el acuerdo zanjaba, al menos momentáneamente la expulsión sufrida. Sólo 
restaba que las instituciones estatales asumieran la responsabilidad de apoyar con enseres y víveres a las familias desplazadas, ${ }^{65} \mathrm{y}$, por supuesto, faltaba su retorno.

El día 24 de noviembre fueron liberadas las personas inculpadas por las agresiones sufridas por los evangélicos a principios de año. ${ }^{66}$ Ese mismo día retornaron los expulsados en dos microbuses que fueron acompañados por comisionados de diversas instituciones estatales, así como por el obispo Felipe Arizmendi y pastores evangélicos. Incluso en el acto estuvo presente el Gobernador del estado, Pablo Salazar, quien se encargó de llevar a las tres personas liberadas a su comunidad de origen. El retorno a la supuesta normalidad comunal se convirtió en un acto político con discursos de las partes involucradas y del gobernador, ${ }^{67}$ prueba de ello es que los dirigentes de la CIOAC-Histórica fueron los que ofrecieron la comida en la casa ejidal. ${ }^{68}$

El retorno se había producido, sin embargo, una tarjeta informativa fechada el 22 de noviembre, dos días antes de su arribo a Justo Sierra, sembraba la duda sobre la solución final al conflicto, y la manera en que se iba a resolver. En ella se anunció que las familias desplazadas permanecerían sólo 90 días en la localidad, puesto que aceptaron ser reubicadas en el anexo Quishte, "colindante con la comunidad González de León y en este lapso el INVI, se comprometió a construir 25 viviendas para igual número de familias y la SEPI, donará 64 hojas de lámina, una tonelada de maíz y una tonelada de frijol". ${ }^{69}$

El anexo no se construyó y en la actualidad no existen indicios, al menos en fechas recientes, de que el problema pueda avivarse.

Qué conclusión podemos obtener de esta descripción en los dos aspectos que arriba mencionamos como destacables del territorio descrito. En primer lugar la similitud con otros casos producidos en la misma región política Fronteriza, atravesados todos por una variedad de siglas políticas u organizaciones sociales o campesinas. Es decir, todos los llamados conflictos religiosos desatados en el municipio de Las Margaritas han mostrado que los involucrados, ya sean evangélicos expulsados o católicos expulsadores están ligados a algún tipo de organización política, social o de producción y que, en buena medida, estas filiaciones influyen, por no afirmar que determinan, la dirección que el conflicto adquiere. En muchos casos, aunque en el de Justo Sierra sólo aparece una familia, los expulsados no son sólo evangélicos, sino también católicos, lo cual remite a una aporía en el razonamiento mismo del carácter religioso del conflicto.

En este sentido, la realidad que ofrece el caso de Justo Sierra, ejemplo del municipio de Las Margaritas, contrasta, como segundo elemento a destacar, con lo acontecido en la región Altos de Chiapas. Ahí el modelo del tradicionalismo religioso, a pesar de sus nexos con los controles políticos y económicos municipales, se confronta a una disidencia que a través de la asunción del evangelismo cuestiona formas de ejercer el poder y gastos suntuarios realizados de manera obligatoria. El control político y económico, en buena medida soterrado bajo el tradicionalismo religioso, tiene en el evangelismo una contraparte única, cualquiera que sea la adscripción religiosa elegida.

En este sentido, la situación del municipio de Las Margaritas, y el caso de Justo Sierra ha querido ejemplificarlo, muestra cómo el problema no enfrenta a un modelo de sociedad definido, con críticas agrupadas solamente en el evangelismo, como sería el caso de Chamula en los Altos de Chiapas, sino que ofrece un abanico de actores y propuestas, variables dependiendo de la localidad. De tal suerte que, y con ello terminamos, las confrontaciones denominadas religiosas han parecido más enfrentamientos entre modelos disímiles de sociedad, concretamente de comunidad. Modelos que desde los credos religiosos, pasando por las corrientes internas del catolicismo, los partidos políticos, las organizaciones sociales y productivas o el EZLN, visible este último también en la región, han querido o siguen pretendiendo establecer su pauta de organización interna comunitaria como el único modelo existente, tomando 
como soportes para ello elementos de la tradición, de las recientes propuestas políticas o religiosas. El conflicto religioso, en este sentido, no es el conflicto en sí, sino la cara más visible de los enfrentamientos que atraviesan esta región y, en particular, el municipio de Las Margaritas.

\section{Abreviaturas}

RAN Registro Agrario Nacional

SAR Subsecretaría de Asuntos Religiosos

(Gobierno del Estado de Chiapas)

\section{Notas}

${ }^{1}$ Este ensayo es resultado del proyecto «La diversidad religiosa en Chiapas. Alcances y límites de la pluralidad y la tolerancia» realizado conjuntamente con Carolina Rivera Farfán, María del Carmen García e Irene Sánchez Franco. Fue financiado por la Subsecretaría de Asuntos Religiosos del Gobierno del Estado de Chiapas y la Subsecretaría de Población, Migración y Asuntos Religiosos del Gobierno Federal.

${ }^{2}$ Véase, por ejemplo, Número Uno, 10-03-1993.

${ }^{3}$ Véase Cuarto Poder, 30-04-1993.

${ }^{4}$ De la región Fronteriza de Chiapas en su división política territorial.

${ }^{5}$ Gobierno Municipal Constitucional del Municipio de Las Margaritas, Chiapas, Plan de Desarrollo, 2002-2004.

${ }^{6}$ Periódico Oficial del Gobierno del Estado, t. LIII, núm. 16, Tuxtla Gutiérrez, 15 de abril de 1936,p. 4.

${ }^{7}$ Periódico Oficial del Gobierno del Estado, Alcance al núm. 5, Tuxtla Gutiérrez, 4 de febrero de 1942.

${ }^{8}$ Para una información más amplia sobre los trámites agrarios véase RAN, Expedientes 800 y 800-2.

${ }^{9}$ Entrevista con el pastor Antonio Alfaro, Las Margaritas, 24-04-2002.

${ }^{10}$ Entrevista con el pastor Antonio Alfaro, Las Margaritas, 24-04-2002.

${ }^{11}$ SAR, Expediente Justo Sierra, S.C., Tarjeta informativa, San Cristóbal de Las Casas, 12 de septiembre de 2000.

${ }^{12}$ Ibid., Tarjeta informativa, San Cristóbal de Las Casas, 25 de octubre de 2000.

${ }^{13}$ Ibid., Jesús Manuel Grajales, Subsecretario de Asuntos Religiosos a Eduardo Montoya, Procurador de Justicia, Tuxtla Gutiérrez, 25 de octubre de 2000.
${ }^{14}$ Ibid., Minuta de trabajo, Las Margaritas, 26 de octubre de 2000. ${ }^{15}$ Ibid., A. Gerardo Constantino, Visitador Adjunto de la CEDH a Jorge Mario Lescieur, Secretario de Gobierno, Tuxtla Gutiérrez, 26 de octubre de 2000 y Servando Cruz, Director de Asuntos Jurídicos a Jesús Manuel Grajales, Subsecretario de Atención Religiosa, Tuxtla Gutiérrez, 26 de octubre de 2000. ${ }^{16}$ Ibid., Acta de Acuerdo, Ejido Justo Sierra, Las Margaritas, 11 de enero de 2001.

${ }^{17} \mathrm{Ibid}$., Los representantes evangélicos a Rafael Guillén, Delegado de Gobierno en la región Fronteriza, 15 de enero de 2001.

${ }^{18}$ Ibid., José María Morales, Subsecretario de Asuntos Religiosos a Mauricio Gándara, Secretario de Seguridad, Tuxtla Gutiérrez, 15 de enero de 2001.

${ }^{19}$ Ibid., Rafael Guillén, Delegado de Gobierno en la región Fronteriza a Mauricio Gándara, Secretario de Seguridad, Comitán, 19 de enero de 2001.

${ }^{20}$ Ibid., José María Morales, Subsecretario de Asuntos Religiosos a Emilio Zebadúa, Secretario de Gobierno, Tuxtla Gutiérrez, 1 de febrero de 2001.

${ }^{21}$ Ibid., José María Morales, Subsecretario de Asuntos Religiosos a Guillermo Méndez Sántiz, Presidente de Bienes Comunales; Antonio Vázquez Pérez, Presidente del Comisariado Ejidal y Melquiades Hernández Méndez, Agente Municipal, Tuxtla Gutiérrez, 1 de febrero de 2001.

${ }^{22}$ Ibid., Documento informativo, s.f.

${ }^{23}$ Nueva localidad que según el entonces Subsecretario de Asuntos Religiosos del Gobierno del Estado, José María Morales, había sido solicitado desde un principio por los evangélicos, sin que el gobierno lo aceptara. Incluso señaló que la problemática religiosa se agrava cuando en la prensa aparece la solicitud del anexo efectuada por los evangélicos. Entrevista realizada el 03 de febrero de 2004.

${ }^{24}$ Ibid., Tarjeta informativa, Rafael Guillén, Delegado de Gobierno en la región Fronteriza a Rubisel Guillén, Subsecretario de Operación Regional, Comitán, 8 de febrero de 2001.

${ }^{25}$ Unos meses más tarde, un funcionario público insistía todavía en que la mesa de negociación debía elegir entre las alternativas del retorno de los desplazados o la creación de un anexo. Ibid., Gabriel Gutiérrez Ávila, Subsecretario de Gobierno a Emilio Zebadúa, Secretario de Gobierno, Tuxtla Gutiérrez, 7 de abril de 2001.

${ }^{26}$ Ibid., Organización de Pueblos Evangélicos Tojolabales a José M. Morales, Las Margaritas, 20 de febrero de 2001.

${ }^{27}$ SAR, Expediente Justo Sierra, S.C., Jesús David Pineda, Visitador de la Comisión Estatal de Derechos Humanos a 
Emilio Zebadúa, Secretario de Gobierno, Tuxtla Gutiérrez, 22 de febrero de 2001.

${ }^{28}$ Ibid., Gilberto Ocaña a José María Morales, Tuxtla Gutiérrez, 23 de febrero de 2001.

${ }^{29}$ Ibid., José María Morales a Mauricio Gándara, 23 de febrero de 2001.

${ }^{30}$ La averiguación previa tenía el número AL94/164/2001.

${ }^{31}$ SAR, Expediente Justo Sierra, S.C., Miguel Angel Yáñez Mijangos, Subprocurador de Justicia Zona Altos a Milton Escobar Castillejos, Subprocurador General de Justicia, San Cristóbal Las Casas, 24 de febrero de 2001.

${ }^{32}$ Ibid., Los Expulsados a Rafael Guillén, Delegado de Gobierno en la región Fronteriza, Comitán, 24 de febrero de 2001.

33 Ibid., Rafael Guillén, Delegado de Gobierno en la región Fronteriza a Emilio Zebadúa, Secretario de Gobierno, Comitán, 24 de febrero de 2001 . Véase nota 38 donde se argumenta lo contrario.

${ }^{34}$ Ibid.

35 Ibid., José María Morales, Subsecretario de Asuntos Religiosos a Emilio Zebadúa, Secretario de Gobierno, Tuxtla Gutiérrez, 25 de febrero de 2001. Un oficio del Presidente Municipal de Las Margaritas, fechado el 26 de febrero de 2001, dirigido al Secretario de Gobierno, Emilio Zebadúa, informa que el ayuntamiento apoyó de manera emergente a los desplazados con " 20 colchonetas matrimoniales, 25 cobertores, 25 desayunos, así como 10 despensas”.

${ }^{36}$ Ibid.

${ }^{37}$ Ibid., José de la O Bamaca, Director de Estudios y Análisis de Asuntos Religiosos a José María Morales, Subsecretario de Asuntos Religiosos, Tuxtla Gutiérrez, 7 de marzo de 2001. El mismo día, un oficio de Horacio Schroeder, Subsecretario de Protección Civil dirigido al Gobernador del Estado, Pablo Salazar, señalaba que "se hizo entrega de los apoyos para las 134 personas desplazadas de la comunidad [...], consistentes en 1260 litros de agua embotellada, 30 cajas de galletas, 120 cobertores, 50 colchonetas, $402 \mathrm{~kg}$ de harina de maíz, 402 latas de atún, $402 \mathrm{~kg}$ de frijol, 201 lt de aceite, 804 bolsas de sopa de pasta y 804 sobres de atole; con ello se está en condiciones de sufragar sus necesidades básicas de alimentación, abrigo y estancia durante 15 días aproximadamente.

El apoyo fue entregado en coordinación con la Subsecretaría de Asuntos Religiosos, mediante un convenio suscrito por el Presidente Municipal y el Presidente de la Organización de Pueblos Evangélicos Tojolabales (OPET), Sr. José Roque Hernández Sántiz".
${ }^{38}$ Ibid.

${ }^{39}$ Ibid., Rafael Guillén, Delegado de Gobierno en la Región Fronteriza a Pablo Salazar, Gobernador del Estado, Comitán, 11 de marzo de 2001.

${ }^{40}$ Ibid., Representantes de los expulsados a José M. Morales, Subsecretario de Asuntos Religiosos, Las Margaritas, 13 de marzo de 2001. La comisión estaría integrada por la Subsecretaria mencionada, el Ayuntamiento Constitucional, la Comisión Estatal de Derechos Humanos y el diputado local Rafael Pinto Cano. Una semana más tarde, Manuel Collazo, Presidente de la OPEACH (Organización Pueblos Evangélicos de los Altos de Chiapas) solicitaba, también, al Gobernador del Estado, la creación de una mesa negociadora que restableciera el orden legal en el caso de Justo Sierra, San Cristóbal de Las Casas, 21 de marzo de 2001.

${ }^{41}$ Ibid., Francisco García Sántiz y Antonio Jiménez López (representantes de los expulsados) a Pablo Salazar, Gobernador del Estado, Las Margaritas, 13 de marzo de 2001. Véase Cuarto Poder, 13-03-2001.

${ }^{42}$ Ibid., Comunicado sin fecha que remite el Presidente Municipal de Las Margaritas a José M. Morales, Subsecretario de Asuntos Religiosos, 13 de marzo de 2001.

${ }^{43}$ Ibid., Tarjeta informativa de la PGJE, 13 de marzo de 2001.

${ }^{44}$ Ibid., Rafael Guillén, Delegado de Gobierno en la región Fronteriza a Rubisel Guillén, Subsecretario de Operación Regional, Comitán, 21 de marzo de 2001. Véase, también, Cuarto Poder, 21-03-2001.

${ }^{45}$ Ibid., Rafael Guillén, Delegado de Gobierno en la región Fronteriza a Emilio Zebadúa, Secretario de Gobierno, Comitán, 26 de marzo de 2001.

${ }^{46} \mathrm{Ibid}$., Nota interna de la Secretaría de Gobierno, 27 de marzo de 2001. En dicho documento se afirma que miembros de la CIOAC oficial acordaron no permitir el regreso a Justo Sierra de dos familias evangélicas, por lo que pensaban proponer su reubicación en un anexo del mismo ejido.

${ }^{47}$ Ibid., Representantes de los expulsados a Comandante de la Policía de Seguridad Pública del Estado, Las Margaritas, 28 de marzo de 2001.

${ }^{48}$ Ibid., José M. Morales, Subsecretario de Asuntos Religiosos a Emilio Zebadúa, Tuxtla Gutiérrez, 29 de marzo de 2001. El mismo Subsecretario siguió solicitando apoyos diversos en fechas siguientes, concretamente a Horacio Schroeder, Subsecretario de Protección Civil, 2 de abril de 2001; a Fidel Yamasaki, Jefe de la Unidad de Apoyo Estatal Progresa, 4 de 
abril de 2001 y a Emilio Zebadúa, Secretario de Gobierno, 17 de abril de 2001.

${ }^{49}$ Ibid., Juan González Esponda, Comisionado para la Reconciliación de Comunidades en Conflicto a José M. Morales, San Cristóbal de Las Casas, 9 de abril de 2001.

${ }^{50} \mathrm{Ibid}$., José M. Morales, Subsecretario de Asuntos Religiosos a Emilio Zebadúa, Secretario de Gobierno, Tuxtla Gutiérrez, 28 de abril de 2001. Con anterioridad a dicha reunión Álvaro Castro, Director General de Asociaciones Religiosas de la Secretaría de Gobernación, instó al Subsecretario de Asuntos Religiosos de Chiapas a salvaguardar "los derechos y libertades que a favor de los individuos consagra nuestra Carta Magna", México D.F., 17 de abril de 2001.

${ }^{51}$ Ibid., Francisco García Sántiz y Antonio Jiménez López, Representantes de los Expulsados a José M. Morales, Subsecretario de Asuntos Religiosos, Las Margaritas, 21 de mayo de 2001.

52 “...las órdenes de aprehensión en contra de católicos miembros de la CIOAC-oficial, se encuentran archivados (sic) por lo que se trata de "amigos" del delegado de gobierno Rafael Guillén Domínguez, "lo puso el camarón” [Luis Hernández Cruz] por eso no puede actuar en su contra, porque tiene compromisos, pero nosotros estamos cansados y tomaremos medidas de presión, se acabó nuestra paciencia denunció el indígena”, Cuarto Poder, 25-05-2001, p. 22.

${ }^{53}$ Ibid., Jesús David Pineda Carpio, Visitador Adjunto de la Comisión Estatal de Derechos Humanos a Emilio Zebadúa, Secretario de Gobierno, Comitán, 16 de junio de 2001.

${ }^{54}$ Ibid., José M. Morales, Subsecretario de Asuntos Religiosos a Emilio Zebadúa, Secretario de Gobierno, Tuxtla Gutiérrez, 27 de junio de 2001.

${ }^{55}$ Ibid., Gabriel Gutiérrez Ávila, Subsecretario de Gobierno a Emilio Zebadúa, Secretario de Gobierno, Tuxtla Gutiérrez, 29 de junio de 2001.

56 "Después de cuatro meses de espera, en este momento su Gobierno ha dad un importante paso al aplicar la ley para encontrar la solución pacífica y duradera anhelada por nuestros hermanos expulsados. Exigimos que este proceso asegure la integridad física y moral de cada una de las personas expulsadas; que les sean restituidas sus pertenencias y sean satisfechas sus necesidades de vivienda, salud y educación. No obstante esperamos que el encarcelamiento no sea una simulación y que al mismo tiempo sean respetados sus derechos", Ibid., Marcos Alfaro Solis, Presidente del CEIECH a Pablo Salazar, Gobernador del Estado, Tuxtla Gutiérrez, 29 de junio de 2001.
${ }^{57}$ Ibid., Tarjeta informativa de la PGJE, 1 de julio de 2001.

${ }^{58}$ Ibid., Comisariado Ejidal, Secretario del Comisariado y Suplente del Agente Municipal de Justo Sierra a Pablo Salazar, Gobernador del Estado, Justo Sierra, Las Margaritas, 5 de julio de 2001.

${ }^{59}$ Ibid., José M. Morales, Subsecretario de Asuntos Religiosos a Emilio Zebadúa, Secretario de Gobierno, Tuxtla Gutiérrez, 16 de agosto de 2001.

${ }^{60}$ Ibid., Francisco[García Sántiz], Antonio[Jiménez López] y Rosario[Gordillo Méndez], Representantes de los Expulsados a Pablo Salazar, Gobernador del Estado, Las Margaritas, 20 de agosto de 2001.

${ }^{61}$ Ibid., con papel membretado del CEDECH, Representantes de los Expulsados a Pablo Salazar, Gobernador del Estado, Las Margaritas, 5 de septiembre de 2001.

${ }^{62}$ Ibid., 61 firmantes a Rafael Guillén, Delegado de Gobierno en la región Fronteriza, Las Margaritas, 11 de noviembre de 2001.

${ }^{63}$ Firma que según el entonces Subsecretario de Asuntos Religiosos del Gobierno del Estado, José María Morales, se produjo gracias a la intervención del Presidente Municipal electo, miembro del PRD, así como de Arturo Luna, funcionario estatal que durante muchos años fue destacado dirigente de la CIOAC. Entrevista realizada el 03 de febrero de 2004.

${ }^{64}$ Ibid., Convenio de Reconciliación, Las Margaritas, 16 de noviembre de 2001.

${ }^{65}$ Ibid., Rafael Guillén, Delegado de Gobierno en la región Fronteriza a José M. Morales, Subsecretario de Asuntos Religiosos, Comitán, 19 de noviembre de 2001, "Relación de Necesidades Presentada por los Evangélicos de Justo Sierra". ${ }^{66}$ Ibid., Gabriel Gutiérrez Ávila, Subsecretario de Gobierno a Emilio Zebadúa, Secretario de Gobierno, Tuxtla Gutiérrez, 24 de noviembre de 2001.

${ }^{67}$ ، Tenemos que cerrar el eslabón de la violencia sembrando la semilla de la paz en los corazones de todos los chiapanecos, para paso a una reconciliación duradera en Chiapas', dijo el gobernador Pablo Salazar Mendiguchía al acompañar el retorno de 26 familias de la comunidad Justo Sierra...", Diario de Chiapas, 25-11-2001.

${ }^{68}$ Ibid., Gabriel Gutiérrez Ávila, Subsecretario de Gobierno a Emilio Zebadúa, Secretario de Gobierno, Tuxtla Gutiérrez, 24 de noviembre de 2001.

${ }^{69}$ Ibid., Tarjeta Informativa, PGJE-10, 22 de noviembre de 2001. 